\title{
Risk Factors Associated with Under-Five Stunting, Wasting, and Underweight Based on Ethiopian Demographic Health Survey Datasets in Tigray Region, Ethiopia
}

\author{
Berhanu Teshome Woldeamanuel $\mathbb{D}^{1}$ and Tigist Tigabie Tesfaye ${ }^{2}$ \\ ${ }^{1}$ Department of Statistics, Salale University, P.O. Box: 254, Fiche, Ethiopia \\ ${ }^{2}$ Department of Statistics, Mekelle University, P.O. Box: 231, Mek'ele, Ethiopia \\ Correspondence should be addressed to Berhanu Teshome Woldeamanuel; berteshome19@gmail.com
}

Received 30 April 2019; Revised 5 July 2019; Accepted 4 December 2019; Published 20 December 2019

Academic Editor: Mohammed S. Razzaque

Copyright ( 2019 Berhanu Teshome Woldeamanuel and Tigist Tigabie Tesfaye. This is an open access article distributed under the Creative Commons Attribution License, which permits unrestricted use, distribution, and reproduction in any medium, provided the original work is properly cited.

\begin{abstract}
Background. Stunting, wasting, and underweight among children are major problems in most regions of Ethiopia, including the Tigray region. The main objective of this study was to assess the risk factors associated with stunting, wasting, and underweight of children in the Tigray region. Methods. The information collected from 1077 children born 5 years before the survey was considered in the analysis. Multivariable binary logistic regression analysis was fitted to identify significant risk factors associated with stunting, wasting, and underweight. Results. Male children and rural born were having a higher burden of both severe and moderate stunting, wasting, and underweight than females and urban born. Among male children, 27.6\%, $4.10 \%$, and $14.2 \%$ of them were stunted, wasted, and underweight, respectively. Protected drinking water (odds ratio $(\mathrm{OR})=0.68 ; 95 \%$ confidence interval $(\mathrm{CI}):(0.50,0.92))$ was associated with stunting. Maternal age at birth less than 20 years $(\mathrm{OR}=0.66 ; 95 \% \mathrm{CI}$ : $(0.45,0.97))$ and being male $(\mathrm{OR}=2.04 ; 95 \% \mathrm{CI}:(1.13,3.68))$ were associated with high risk of underweight. No antenatal care follow-up $(\mathrm{OR}=2.20 ; 95 \% \mathrm{CI}$ : $(1.04,4.64))$ was associated with wasting, while the poor wealth index, diarrhea, low weight at birth $(<2.5 \mathrm{~kg})$, lower age of a child, and 3 or more under-five children in a household were significantly associated with stunting, wasting, and underweight. Conclusions. Being born in rural, being male, unprotected drinking water, smaller weight at birth, no antenatal follow-ups, diarrhea, and poor household wealth were factors associated with increased stunting, wasting, and underweight. Thus, interventions that focus on utilization of antenatal care services, improving household wealth, and improving access to protected drinking water were required by policymakers to decrease stunting, wasting, and underweight more rapidly.
\end{abstract}

\section{Introduction}

Globally, about 151 million children under 5 years of age suffer from chronic malnutrition and 67 million under-five were wasted in 2017 [1]. Among these malnourished underfive, $55 \%$ of all stunted children under 5 years of age have been from Asia and 39\% were living in Africa, while 69\% of all wasted children under 5 years of age resided in Asia and $27 \%$ of wasted under-five lived in Africa. Moreover, UNICEF, WHO, and World Bank Group Joint Child Malnutrition estimate in 2018 that about $35.60 \%$ of under-five in east Africa were stunted [2].
Malnutrition among under-five declined from $32.6 \%$ to 22.2\% between 2000 and 2017 worldwide [3]. In 2018, UNICEF reported that about 3.1 million children died of undernutrition and malnutrition contributes to more than half of global child deaths [4]. Though there is a global decline in the malnutrition rates of under-5, the risk of malnutrition remains high and it is the major cause of under-five morbidities and mortalities of African especially sub-Saharan Africa [5]. Burundi has the highest stunting (57.7\%) followed by Malawi (47.1\%); Niger has the highest wasting (18\%), followed by Burkina Faso (15.5\%); and Burundi has the highest underweight (28.8\%), followed by 
Niger (36.4\%), Chad (28.8\%), and Nigeria (28.7\%). Ethiopia also has high wasted (8.70\%) and underweight $(25.2 \%)$ among East African countries. In 2010, about 39.4\%, 24.9\%, and $10.3 \%$ of under-five in Africa were stunted, underweight, and wasted, respectively [6]. In 2015, the undernutrition in sub-Saharan African accounts for one-third of the global estimate [7].

According to the Ethiopian Demographic and Health Survey 2016, the Tigray region has $39.3 \%, 23 \%$, and $11.1 \%$ of stunting, underweight, and wasting, respectively. Moreover, $13.4 \%$ of under-five were experiencing severe stunting, $3.40 \%$ had severe wasting, and $5.20 \%$ had severe underweight [8]. Though Ethiopia achieved a Millennium Development Goal 4 (MDG4) of the child mortality reduction, the country still experiences an increment of stunting, wasting, and underweight cases, where the Tigray region had the rates of stunting, wasting, and underweight above the national average [9].

Previous research studies conducted in the Tigray region revealed that $46.9 \%, 33 \%$, and $11.6 \%$ of under-five were stunted, underweight, and wasted [10]. A study conducted on the trend of malnutrition in the Tigray region showed that $33 \%$ and $51 \%$ of under-five mortality were due to severe acute malnutrition in 2011 and 2015 [11]. Another study done in Adi-Harush and Hitsats refugee camps in the Tigray region indicates $37 \%, 21.6 \%$, and $11 \%$ of children aged $6-59$ months were stunted, underweight, and wasted, respectively [12]. A similar study on malnutrition and associated factors of underfive based on hospital data in the west Arsi zone of the Oromia region showed that the magnitude of stunting, underweight, and wasting was about $38.3 \%, 49.2 \%$, and $25.2 \%$, respectively [13]. On the other hand, in the east Gojjam Zone of the Amhara region, $44.7 \%$ of stunting, $15.3 \%$ of underweight, and $10.0 \%$ of wasting were reported [14].

The determinants of stunting, wasting, and underweight are significantly associated with socioeconomic and demographic characteristics of mothers and children and environmental factors. Maternal education status was found to be strongly inversely associated with under-five stunting, underweight, and wasting [15-22]. Maternal age was also a significant determinant of under-five stunting and underweight $[15,23]$.

Other determinants of stunting, wasting, and underweight include the place of residency [23], the number of under-five children in households $[15,23,24]$, birth order $[23,25]$, sources of improved drinking water $[16,23]$, and toilet facility [23]. There is also a strong and positive association between antenatal care service utilization and child stunting/chronic malnutrition [23]. Most studies also found that sex of a child $[15,17,23,25]$, child age $[13,15,23-25]$, and household wealth index $[15,17,24,26]$ were found to be significant risk factors of under-five stunting, wasting, and underweight. Further, earlier studies from Ethiopia show that factors associated with increased risk of under-five stunting include baby weight at birth [16], short duration of exclusive breastfeeding [16, 24, 25, 27-29], minimum dietary diversity and meal frequency $[19,30,31]$, and diarrhea in the past 2 weeks $[17,24]$.
Despite the fact that a number of studies have been done on the identification of factors that are associated with under-5 stunting, wasting, and underweight in the Tigray region, none of them uses the nationally representative data for the Tigray region. The progress made in decreasing under-five stunting, wasting, and underweight in the region is still high, and more effort is needed to improve the barriers for further reduction. More research studies are, therefore, required to inform policymakers to implement appropriate intervention programs. To address this gap, we conducted an all-inclusive cross-sectional analysis of the recent 2016 Ethiopian Demographic Health Survey, to assess the risk factors for stunting, wasting, and underweight. Therefore, the main objective of this study was to assess the risk factors associated with stunting, wasting, and underweight of under-five in the Tigray region.

\section{Materials and Methods}

2.1. Description of the Study Area. The Tigray National Regional State is located in the northern part of Ethiopia. According to the 2007 Census, the state's population size was $3,136,267$ of which $1,594,102$ were females. The urban residents of the region were 468,478 and its rural residents $2,667,789$ [32].

2.2. Source of Data. The data onto this study were extracted from the Ethiopian Demographic and Health Survey (EDHS) 2016. The Central Statistics Agency (CSA), the Ministry of Health $(\mathrm{MOH})$, and the Ethiopian Public Health Institute together conducted the survey from January 18, 2016-June 27, 2016, where the United States Agency for International Development (USAID) funded the project. The survey implemented a two-stage sample design. In the first stage, 645 enumeration areas were selected with probability related to size. In the second stage, 28 households per cluster of equal probability systematic were selected from the household list. All women of 15-49 years that were either stable inhabitant or visitors, who lived at least one night in the household before the survey, were eligible for the interview. Data were gathered by conducting face-to-face interviews for women that met the eligibility criteria.

2.3. Variables of the Study. Determinants of stunting, wasting, and underweight in this study were selected from the available similar studies on the subject; the main predictors explored for under-five nutritional status were grouped into demographic, socioeconomic, and environmental factors related to mothers and households. Then, the nutritional status of a child was calculated based on the three anthropometric indicators: wasting (weight-for-height), stunting (height-for-age), and underweight (weight-forage). The dependent variables of this study were stunting, wasting, and underweight among children aged 0-59 months. 
2.4. Statistical Analysis. Data analysis was done using SPSS version 21.0 (2018). The descriptive statistics such as frequencies and proportions were used to summarize the distribution of selected background characteristics of the sample. To estimate the effect of each demographic, socioeconomic, and environmental factors on under-five stunting, wasting, and underweight (odds ratio (OR) with 95\% confidence intervals (CI)), logistic regression analysis was fitted. Bivariate analysis based on Pearson chi-square tests was used for testing association with the predictors and outcome variable under-5 stunting, wasting, and underweight. All significant predictor variables $(p<0.05)$ in the bivariate analysis were included in the multivariate logistic regression analysis. The goodness of fit of the fitted models was checked using the Hosmer and Lemeshow test (HLT).

\section{Results}

3.1. Descriptive Statistics. More than two-thirds of the children were from mothers aged 15-20 years at first birth (67\%). Nearly one child in 10 children was from rural areas (88\%) while the remaining $12 \%$ of the children were living in urban areas. According to Table 1, children from uneducated mothers have a higher percentage $(67.2 \%)$ of samples. Similarly, the highest percentage of children $(52.5 \%)$ belonged to a mother whose husband has no education at all, while only $8 \%$ has a secondary or higher education.

The majority $(42.0 \%)$ of the respondents used unprotected drinking water and $38 \%$ of them used protected well while only one-fifth (20\%) of respondents had piped sources of drinking water. Similarly, more than half $(58.5 \%)$ of the respondents had no toilet facility, and $41.5 \%$ had toilet facilities. More than half $(52.3 \%)$ of respondents had two under-five children in the household, more than one-third $(36.3 \%)$ had one under-five child in households, and only $11.4 \%$ of respondents had at least three children less than five years in households in the past five years preceding the survey. More than half (52.8\%) belonged to the poor wealth index, while $32 \%$ belonged to rich household wealth indices.

About $54 \%$ of children belong to mothers that did not attend any antenatal care services during pregnancy, and only one from five $(22 \%)$ had attended at least four antenatal visits during pregnancy. On the other hand, only $11.40 \%$ of mothers have attended postnatal care services. The percentage of age distribution of samples included in the study was almost consistent with all age groups. The vast majority (86\%) of children included reported that they had no diarrhea two weeks before the survey. Similarly, about $85 \%$ of children born five years before the survey had no anemia. As the vaccination is concerned, $78 \%$ of them have received vitamin $A$ in the last 6 months, about $74 \%$ have received measles, and about $40 \%$ have received tetanus.

Results showed that about $19.4 \%$ of the children were first birth, about $44 \%$ were second, third, or fourth, and $36 \%$ were had birth order at least a fifth. The vast majority $(53.5 \%)$ of women have been engaged in the agricultural sector while $21 \%$ were housewives without a formal job. The proportion of children currently breastfeeding was nearly two-thirds $(63 \%)$, and only $3 \%$ of the under-five included in the study was born through the Cesarean section birth. As high as $89 \%$ of children were born at home outside health facilities and more than $97 \%$ of births were singleton. Concerning birth weight, about $34 \%$ of under-five included in the study had a birth weight less than $2.5 \mathrm{~kg}$, about $46 \%$ had $2.50-4 \mathrm{~kg}$, and $20 \%$ had more than $4 \mathrm{~kg}$ (Table 1 ).

3.2. Bivariate Analysis. According to Table 2, under-five stunting, wasting, and underweight were higher in the rural areas, and about $92.4 \%$ stunted, $89.5 \%$ wasted, and $91.4 \%$ of underweight were reported among rural children born five years before the survey. As indicated in Figure 1, among rural children, $21.5 \%, 2.90 \%$, and $9.30 \%$ were severely stunted, wasted, and underweight, respectively.

Regarding maternal education, the percentage of stunting, wasting, and underweight among children born of the uneducated mother was relatively higher than that of attending at least a primary education. Among children born to a woman with no education, $71.0 \%, 71.9 \%$, and $71.6 \%$ were stunted, wasted, and underweight, respectively. Similarly, stunting, wasting, and underweight among under-five children differed significantly with the partners' level of education, with those of no education, having a higher proportion of experiencing stunting (58.2\%), wasting (52.6\%), and underweight (59.9\%). Only $2.10 \%, 1.80 \%$, and $1.90 \%$ of children born from a woman whose partner has higher education in the last five years prior to the survey were stunted, wasted, and underweight.

As maternal age was concerned, the highest percentage of under-5 stunting, wasting, and underweight was among children belonging to older age women. About 30\%, 23.7\%, and $28 \%$ of under-five children whose mother aged 35 and older were stunted, wasted, and underweight, respectively, while only $3.50 \%, 5.30 \%$, and $4.70 \%$ of children whose mother is $15-19$ years old were stunted, wasted, and underweight, respectively. Similarly, stunting, wasting, and underweight among under-five differed significantly with the sources of drinking water, and those used unprotected well have the highest proportion of stunting (49.4\%), wasting $(40.3 \%)$, and underweight (47.1\%), respectively, while only $15.2 \%, 20.2 \%$, and $15.6 \%$ of children belonging to the household using piped source experienced under-five stunting, wasting, and underweight, respectively. On the other hand, $61.8 \%, 64.9 \%$, and $60.3 \%$ of children belonging to a family with no toilet facilities had experienced underfive stunting, wasting, and underweight, respectively (Table 2).

With regard to mother's antenatal care follow-ups and baby postnatal care visits, the result shows that among children born from mothers who were not receiving any antenatal care, $58.4 \%, 57 \%$, and $61.1 \%$ were stunted, wasted, and underweight, respectively, while 92.6\%, 96.5\%, and $97.7 \%$ of stunting, wasting, and underweight were reported among children who had not attended any postnatal checkup. Similarly, looking at birth weight of a child, high proportion of stunting (41.3\%), wasting (42.1\%), and underweight (48.6\%) was associated with lower birth weight $(<2.50 \mathrm{~kg})$. About $46 \%, 55 \%$, and $44 \%$ of stunting, wasting, 
TABLE 1: Background characteristics of respondents in the Tigray Region, Ethiopia $(n=1077)$.

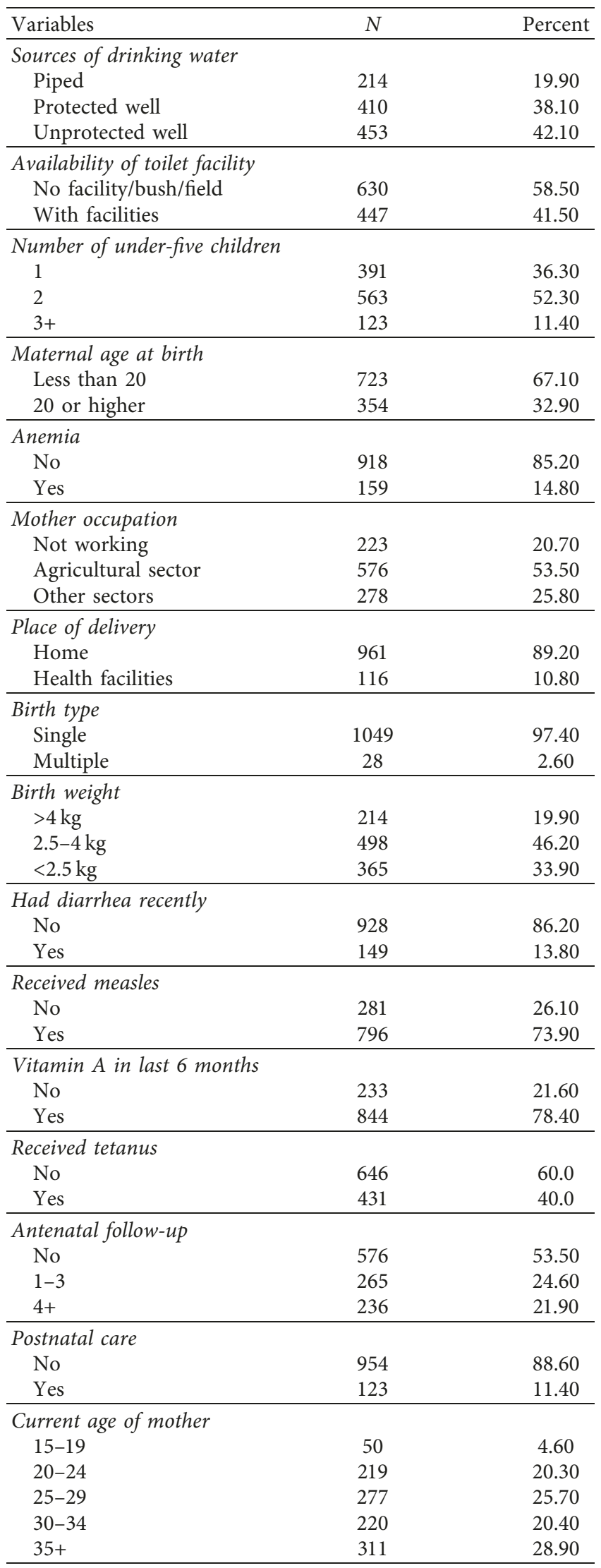

TABle 1: Continued.

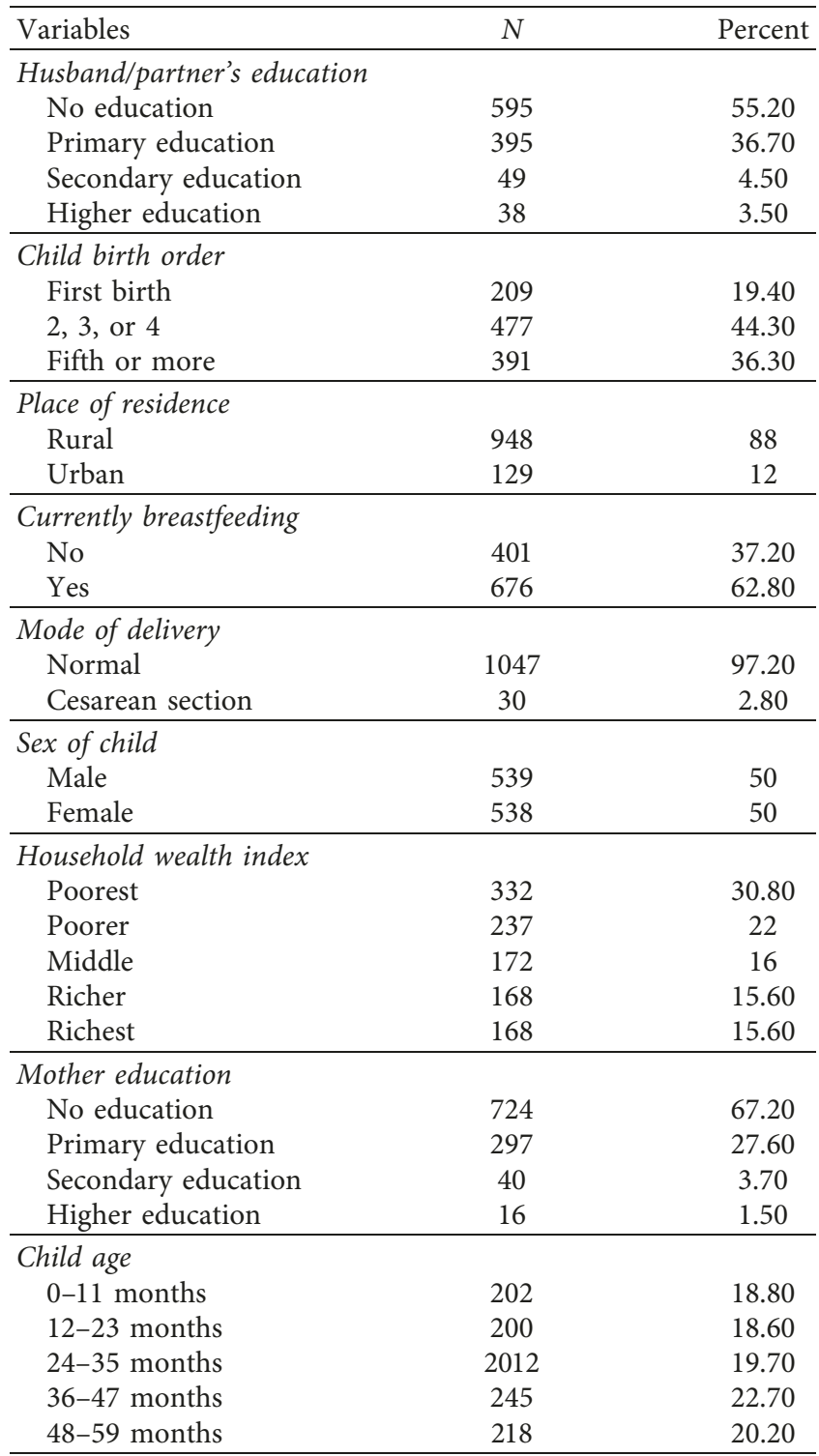

and underweight were reported among children with second, third, or fourth birth order. Also, the percentage of stunting increases with child age between 2 and 4 years and the lowest proportion of stunting was reported among infants.

Stunting, wasting, and underweight also vary with the number of under-five children in households, where $49.9 \%$, $55.3 \%$, and $50.6 \%$ of under-five from families with two underfive children in families had stunted, wasted, and underweight, respectively. The highest percentage of stunting (49.1\%), wasting (48.2\%), and underweight (56.8\%) was observed among children whose mothers are working in the agricultural sector. Also, high percentages of under-five stunting (36.1\%), wasting (28.10\%), and underweight (36.6\%) were reported among children belonging to households with the poor economic level, unlike minimum percent of stunting (9.30\%), wasting $(11.4 \%)$, and underweight $(9.30 \%)$ was 
TABLE 2: Bivariate analysis of stunting, wasting, and underweight by background characteristics of the mother and a child.

\begin{tabular}{|c|c|c|c|c|}
\hline Background characteristics & Categories & Stunting (\%) & Wasting (\%) & Underweight (\%) \\
\hline \multirow{3}{*}{ Sources of drinking water } & Piped & 15.2 & 20.2 & 15.6 \\
\hline & Protected well & 35.4 & 39.5 & 37.4 \\
\hline & Unprotected well & 49.4 & 40.3 & 47.1 \\
\hline \multirow{2}{*}{ Availability of toilet facility } & No facility/bush/field & 61.8 & 64.9 & 60.3 \\
\hline & With facilities & 38.2 & 35.1 & 39.7 \\
\hline \multirow{3}{*}{ Number of under-five children } & 1 & 34.9 & 29.8 & 33.4 \\
\hline & 2 & 49.9 & 55.3 & 50.6 \\
\hline & $3+$ & 15.2 & 14.9 & 16 \\
\hline \multirow{3}{*}{ Mother occupation } & Not working & 18.3 & 26.3 & 17.9 \\
\hline & Agricultural sector & 59.1 & 48.2 & 56.8 \\
\hline & Other sectors & 22.6 & 25.5 & 25.3 \\
\hline \multirow{2}{*}{ Birth type } & Single & 96.4 & 95.6 & 95.3 \\
\hline & Multiple & 3.60 & 4.40 & 4.70 \\
\hline \multirow{3}{*}{ Birth weight } & $>4 \mathrm{~kg}$ & 14 & 18.4 & 12.1 \\
\hline & $2.5-4 \mathrm{~kg}$ & 44.7 & 39.5 & 39.3 \\
\hline & $<2.5 \mathrm{~kg}$ & 41.3 & 42.1 & 48.6 \\
\hline \multirow{2}{*}{ Had diarrhea recently } & No & 84.8 & 70.2 & 77.4 \\
\hline & Yes & 15.2 & 29.8 & 22.6 \\
\hline \multirow{3}{*}{ Antenatal follow-up } & No & 58.4 & 57 & 61.1 \\
\hline & $1-3$ & 25.7 & 29.8 & 25.7 \\
\hline & $4+$ & 15.9 & 13.2 & 14.4 \\
\hline \multirow{2}{*}{ Postnatal care } & No & 96.2 & 96.5 & 97.7 \\
\hline & Yes & 3.80 & 3.50 & 2.30 \\
\hline \multirow{5}{*}{ Current age of mother } & $15-19$ & 3.60 & 5.30 & 4.70 \\
\hline & $20-24$ & 19.7 & 20.2 & 19.5 \\
\hline & $25-29$ & 25.4 & 30.7 & 24.1 \\
\hline & $30-34$ & 21.4 & 20.2 & 23.7 \\
\hline & $35+$ & 29.9 & 23.7 & 28 \\
\hline \multirow{4}{*}{ Husband/partner's education } & No education & 58.2 & 52.6 & 59.9 \\
\hline & Primary education & 37.8 & 41.2 & 35.4 \\
\hline & Secondary education & 1.90 & 4.40 & 2.70 \\
\hline & Higher education & 2.10 & 1.80 & 1.90 \\
\hline \multirow{3}{*}{ Child birth order } & First birth & 17.6 & 14 & 18.7 \\
\hline & 2,3 , or 4 & 45.6 & 55.3 & 43.6 \\
\hline & Fifth or more & 36.8 & 30.7 & 37.7 \\
\hline \multirow{2}{*}{ Place of residence } & Rural & 92.4 & 89.5 & 91.4 \\
\hline & Urban & 7.60 & 10.5 & 8.60 \\
\hline \multirow{2}{*}{ Sex of child } & Male & 52.5 & 57.9 & 52.5 \\
\hline & Female & 47.5 & 42.1 & 47.5 \\
\hline \multirow{5}{*}{ Household wealth index } & Poorest & 36.1 & 28.1 & 36.6 \\
\hline & Poorer & 24.5 & 21.9 & 23 \\
\hline & Middle & 14.5 & 19.3 & 16.3 \\
\hline & Richer & 15.7 & 19.3 & 14.8 \\
\hline & Richest & 9.30 & 11.4 & 9.30 \\
\hline \multirow{4}{*}{ Mother education } & No education & 71.3 & 71.9 & 71.6 \\
\hline & Primary education & 25.4 & 23.7 & 25.7 \\
\hline & Secondary education & 2.90 & 2.60 & 1.90 \\
\hline & Higher education & 0.50 & 1.80 & 0.80 \\
\hline \multirow{5}{*}{ Child age } & 0-11 months & 10 & 27.2 & 15.2 \\
\hline & $12-23$ months & 21.9 & 28.1 & 19.8 \\
\hline & 24-35 months & 24.9 & 18.4 & 24.5 \\
\hline & $36-47$ months & 25.2 & 12.3 & 21.8 \\
\hline & $48-59$ months & 18.8 & 14 & 18.7 \\
\hline
\end{tabular}

reported among those children belonging to the richest household. Stunting, wasting, and underweight were also highly variable with the sex of a child in bivariate analysis with male children reporting a higher percentage of stunting (52.5\%), wasting (57.9\%), and underweight (52.5\%). Similarly, $27.6 \%$ of male children were severely stunted, $4.10 \%$ of 


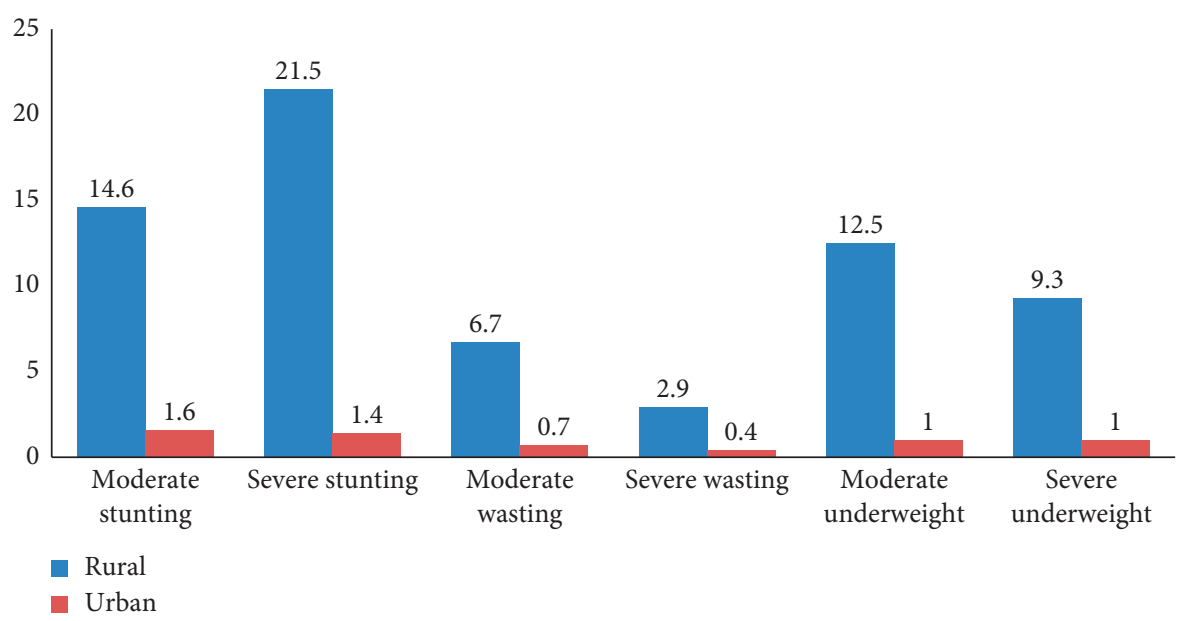

FIgURE 1: Prevalence of stunting, wasting, and underweight by place of residence in the Tigray region, Ethiopia.

male children were severely wasted, and $12.2 \%$ of male children were severely underweight (Figure 2).

In the multivariable logistic regression analysis, sources of drinking water, number of under-five children in a family, child birth weight, measles, tetanus, household wealth index, and child age were statistically significant covariates for stunting. The odds of stunting among children from families using protected drinking water were $0.68(\mathrm{OR}=0.68,95 \%$ CI: $(0.50,0.92))$ times lower than those children belonging to families using unprotected drinking water. Only one child $(\mathrm{OR}=0.55,95 \% \mathrm{CI}:(0.23,0.92))$ and two children $(\mathrm{OR}=0.47,95 \% \mathrm{CI}:(0.30,0.74))$ in a family were associated with decreased odds of stunting compared to those children from households with three or more under-five children. Similarly, birth weights $>4 \mathrm{~kg}(\mathrm{OR}=0.36,95 \% \mathrm{CI}:(0.24$, $0.54)$ ) and $2.50-4 \mathrm{~kg}(\mathrm{OR}=0.60,95 \% \mathrm{CI}:(0.44,0.81))$ were associated with lower odds of stunting. Household wealth index and age of a child were other variables significantly associated with stunting. Children born in the poorest households $(\mathrm{OR}=2.73,95 \% \mathrm{CI}:(1.26,5.93))$ aged between 12 and 23 months $(\mathrm{OR}=1.67,95 \% \mathrm{CI}:(1.01,2.77))$ and 24 and 34 months $(\mathrm{OR}=2.00,95 \% \mathrm{CI}:(1.29,3.10))$ were highly significantly stunted.

Child weight at birth $2.50-4 \mathrm{~kg}(\mathrm{OR}=0.62,95 \% \mathrm{CI}$ : $(0.39,0.99))$ and no diarrhea disease recently $(\mathrm{OR}=0.41$, $95 \%$ CI: $(0.25,0.68))$ had lower odds of wasting, while absence of antenatal care visits during pregnancy $(O R=2.20$, 95\% CI: $(1.04,4.64))$ and child age $0-11$ months $(\mathrm{OR}=3.11$, 95\% CI: $(1.26,7.67)$ ) and between 12 and 23 months $(\mathrm{OR}=2.53,95 \% \mathrm{CI}:(1.16,5.55))$ had a statistically significantly higher odds of wasting.

Results in Table 3 revealed that 2 under-five children in households $(\mathrm{OR}=0.56,95 \% \mathrm{CI}:(0.35,0.91))$, maternal age at birth less than $20(\mathrm{OR}=0.66,95 \% \mathrm{CI}:(0.45,0.97))$, baby weight at birth $>4 \mathrm{~kg}(\mathrm{OR}=0.30,95 \% \mathrm{CI}:(0.19,0.49))$ and $2.50-4 \mathrm{~kg}(\mathrm{OR}=0.48,95 \% \mathrm{CI}:(0.34,0.67))$, no diarrhea disease recently $(\mathrm{OR}=0.34,95 \% \mathrm{CI}:(0.23,0.52))$, the poorest wealth index $(\mathrm{OR}=3.21,95 \% \mathrm{CI}:(1.20,8.56))$, and male sex $(\mathrm{OR}=2.04,95 \% \mathrm{CI}:(1.13,3.68))$ were the factors that have significant impact on underweight (Table 3 ).

\section{Discussion}

The prevalence of stunting, wasting, and underweight in the region was $39.1 \%, 10.6 \%$, and $23.9 \%$, respectively. This figure is lower than the previously reported stunting (46.9\%), wasting (11.6\%), and underweight (33\%) in the region [10]. A similar studies conducted in Hidabu Abote District in Oromia region reported a higher prevalence of stunting (47.6\%), underweight (30.9\%), and wasting (16.7\%) [33]. A similar study conducted in rural Ethiopia also reported $41.2 \%$ of stunting and $27 \%$ of underweight [34], whereas a study conducted in Nigeria reported $47.6 \%$ and $25.6 \%$ of stunting and underweight, respectively [35]. While a study in the Bure Town of West Gojjam Zone (Amhara region) [17] reported lower prevalence of stunting, wasting, and underweight $(24.9 \%, 11.1 \%$, and $14.30 \%$, respectively), another study in Okrika Town of Nigeria [36] also reported $13.6 \%, 8.80 \%$, and $10.5 \%$ prevalence of stunting, wasting, and underweight, respectively. A similar study in east Gojjam Zone [14] reported lower prevalence of underweight (15.3\%) and wasting (10\%), but higher stunting (44.7\%).

In this study, the prevalence of severe stunting $(22.9 \%)$ and underweight $(10.3 \%)$ is markedly higher than the previous studies that reported $7.90 \%$ severely stunting and $3.20 \%$ severely underweight in Bure Town, west Gojjam Zone [17]. Children born in rural areas five years preceding the survey were more likely severely stunted $(21.5 \%)$ and severely underweight (9.30\%) than their urban counterparts. The possible reason for this might be a lack of healthcare and food insecurity programs in rural areas. Moreover, male children are highly severely stunted (27.3\%) and severely underweight $(12.2 \%)$ than females. This figure is higher than that reported in the study in the Bure Town of west Gojjam [17], 10.7\% of severely stunted and $6 \%$ of severely underweight.

In the multivariate logistic regression analysis, it was found that being born of a weight less than $2.50 \mathrm{~kg}$ was associated with a higher risk of stunting, wasting, and underweight than about average $(2.50-4 \mathrm{~kg})$ or larger size at birth $(>4 \mathrm{~kg}$ ). Several studies in the literature reported babies born of smaller size were at higher risk of stunting [15, 37], 


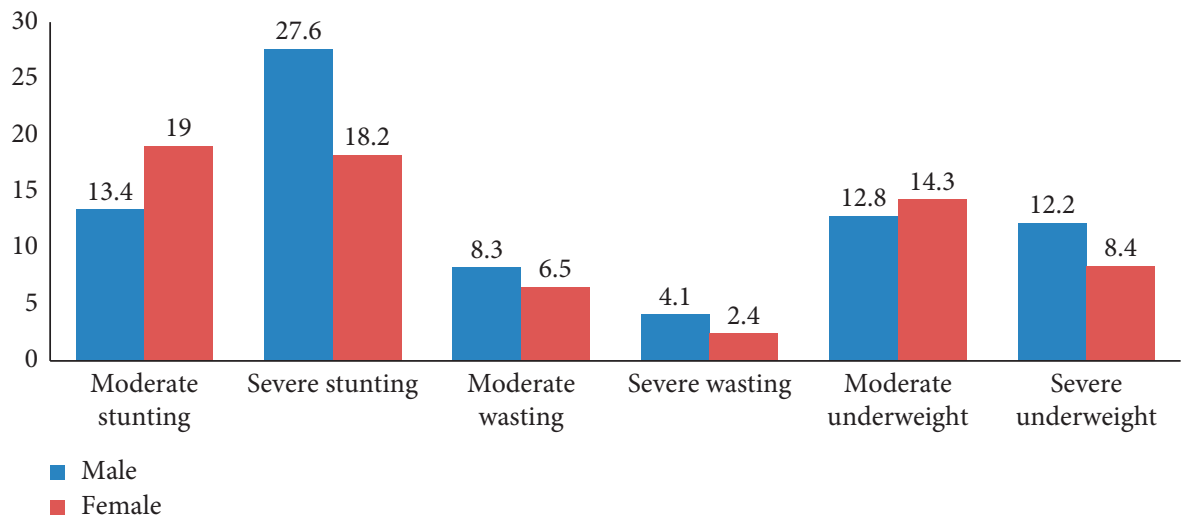

FIgURE 2: Prevalence of stunting, wasting, and underweight by sex of child in the Tigray region, Ethiopia.

TABle 3: Factors associated with stunting, wasting, and underweight among under-five children in Tigray Regional State, Ethiopia $(n=1077)$.

\begin{tabular}{|c|c|c|c|c|c|c|}
\hline \multirow{2}{*}{ Variables } & \multicolumn{2}{|c|}{ Stunting } & \multicolumn{2}{|c|}{ Wasting } & \multicolumn{2}{|c|}{ Underweight } \\
\hline & AOR & $95 \% \mathrm{CI}$ & AOR & $95 \% \mathrm{CI}$ & AOR & $95 \% \mathrm{CI}$ \\
\hline \multicolumn{7}{|c|}{ Sources of drinking water (unprotected) } \\
\hline Piped & 0.94 & $0.57,1.53$ & 0.22 & $0.77,3.25$ & 1.01 & $0.57,1.77$ \\
\hline Protected well & $0.68^{*}$ & $0.50,0.92$ & 0.44 & $0.75,1.96$ & 0.91 & $0.64,1.28$ \\
\hline \multicolumn{7}{|c|}{ Availability of toilet facility (with facilities) } \\
\hline No facility/bush/field & 0.96 & $0.71,1.314$ & 1.36 & $0.83,2.22$ & 0.86 & $0.60,1.21$ \\
\hline \multicolumn{7}{|c|}{ Number of under-five children (3+) } \\
\hline 1 & $0.55^{*}$ & $0.23,0.92$ & 0.73 & $0.33,1.58$ & 0.61 & $0.34,1.07$ \\
\hline 2 & $0.47^{* *}$ & $0.30,0.74$ & 0.82 & $0.43,1.58$ & $0.56^{*}$ & $0.35,0.91$ \\
\hline \multicolumn{7}{|c|}{ Maternal age at birth (20 or higher) } \\
\hline Less than 20 & 0.99 & $0.71,1.41$ & 0.88 & $0.51,1.52$ & $0.66^{*}$ & $0.45,0.97$ \\
\hline \multicolumn{7}{|l|}{ Anemia (yes) } \\
\hline No & 0.75 & $0.51,1.10$ & 1.42 & $0.75,2.68$ & 0.81 & $0.53,1.23$ \\
\hline \multicolumn{7}{|c|}{ Mother occupation (other sectors) } \\
\hline Not working & 1.07 & $0.70,1.64$ & 1.34 & $0.73,2.49$ & 0.79 & $0.48,1.27$ \\
\hline Agricultural sector & 1.18 & $0.82,1.68$ & 0.80 & $0.46,1.38$ & 0.80 & $0.53,1.19$ \\
\hline \multicolumn{7}{|l|}{ Birth type (multiple) } \\
\hline Single & 0.68 & $0.29,1.63$ & 0.82 & $0.26,2.58$ & 0.55 & $0.23,1.33$ \\
\hline \multicolumn{7}{|l|}{ Birth weight $(<2.5 \mathrm{~kg})$} \\
\hline$>4 \mathrm{~kg}$ & $0.36^{* *}$ & $0.24,0.54$ & 0.65 & $0.35,1.18$ & $0.30^{* *}$ & $0.19,0.49$ \\
\hline $2.5-4 \mathrm{~kg}$ & $0.60^{* *}$ & $0.44,0.81$ & $0.62^{*}$ & $0.39,0.99$ & $0.48^{* *}$ & $0.34,0.66$ \\
\hline \multicolumn{7}{|c|}{ Had diarrhea recently (yes) } \\
\hline No & 0.71 & $0.47,1.06$ & $0.41^{* *}$ & $0.25,0.68$ & $0.34^{* *}$ & $0.23,0.52$ \\
\hline \multicolumn{7}{|l|}{ Received measles (yes) } \\
\hline No & $0.53^{*}$ & $0.36,0.79$ & 0.86 & $0.47,1.55$ & 0.78 & $0.50,1.21$ \\
\hline \multicolumn{7}{|c|}{ Vitamin $A$ in last 6 months (yes) } \\
\hline No & 0.92 & $0.64,1.33$ & 0.77 & $0.44,1.34$ & 0.91 & $0.61,1.37$ \\
\hline \multicolumn{7}{|l|}{ Received tetanus (yes) } \\
\hline No & $0.71^{*}$ & $0.50,0.99$ & 1.03 & $0.62,1.70$ & 0.81 & $0.55,1.19$ \\
\hline \multicolumn{7}{|c|}{ Antenatal follow-up (4+) } \\
\hline No & 1.56 & $0.98,2.47$ & $2.20^{*}$ & $1.04,4.64$ & 1.49 & $0.88,2.53$ \\
\hline $1-3$ & 1.34 & $0.87,2.06$ & 1.89 & $0.93,3.87$ & 1.38 & $0.83,2.29$ \\
\hline \multicolumn{7}{|l|}{ Postnatal care (yes) } \\
\hline No & 0.95 & $0.46,1.94$ & 1.49 & $0.48,4.63$ & 2.01 & $0.79,5.13$ \\
\hline \multicolumn{7}{|c|}{ Current age of mother (35+) } \\
\hline $15-19$ & 0.56 & $0.21,1.50$ & 1.20 & $0.29,5.03$ & 1.51 & $0.51,4.47$ \\
\hline $20-24$ & 0.82 & $0.43,1.54$ & 0.90 & $0.34,2.35$ & 1.29 & $0.62,2.65$ \\
\hline $25-29$ & 0.94 & $0.56,1.57$ & 1.10 & $0.51,2.39$ & 1.36 & $0.76,2.44$ \\
\hline $30-34$ & 1.03 & $0.68,1.55$ & 0.97 & $0.51,1.88$ & 1.42 & $0.90,2.26$ \\
\hline
\end{tabular}


TABLE 3: Continued.

\begin{tabular}{|c|c|c|c|c|c|c|}
\hline \multirow{2}{*}{ Variables } & \multicolumn{2}{|c|}{ Stunting } & \multicolumn{2}{|c|}{ Wasting } & \multicolumn{2}{|c|}{ Underweight } \\
\hline & AOR & $95 \% \mathrm{CI}$ & $\mathrm{AOR}$ & $95 \% \mathrm{CI}$ & AOR & $95 \% \mathrm{CI}$ \\
\hline \multicolumn{7}{|c|}{ Husband/partners education (higher education) } \\
\hline No education & 1.39 & $0.50,3.88$ & 1.44 & $0.21,9.95$ & 1.13 & $0.32,4.03$ \\
\hline Primary education & 1.41 & $0.51,3.89$ & 1.90 & $0.28,12.99$ & 1.05 & $0.30,3.72$ \\
\hline Secondary education & 0.63 & $0.19,2.13$ & 1.84 & $0.26,13.20$ & 0.93 & $0.23,3.80$ \\
\hline \multicolumn{7}{|l|}{ Child birth order ( $5^{\text {th }}$ or more $)$} \\
\hline First birth & 1.18 & $0.59,2.36$ & 0.93 & $0.30,2.88$ & 0.90 & $0.41,1.95$ \\
\hline 2,3 , or 4 & 1.29 & $0.83,2.01$ & 1.56 & $0.80,3.07$ & 0.93 & $0.57,1.52$ \\
\hline \multicolumn{7}{|l|}{ Place of residence (urban) } \\
\hline Rural & 1.19 & $0.54,2.62$ & 2.32 & $0.69,7.81$ & 2.28 & $0.85,6.10$ \\
\hline \multicolumn{7}{|l|}{ Currently breastfeeding (yes) } \\
\hline No & 0.95 & $0.66,1.37$ & 1.35 & $0.76,2.42$ & 0.91 & $0.60,1.37$ \\
\hline \multicolumn{7}{|l|}{ Mode of delivery (normal) } \\
\hline Cesarean section & 0.68 & $0.25,1.85$ & 0.99 & $0.17,5.76$ & 1.30 & $0.34,4.93$ \\
\hline \multicolumn{7}{|l|}{ Sex of child (female) } \\
\hline Male & 1.09 & $0.68,1.75$ & 1.86 & $0.82,4.22$ & 2.04 & $1.13,3.68$ \\
\hline \multicolumn{7}{|l|}{ Household wealth index (richest) } \\
\hline Poorest & $2.73^{*}$ & $1.26,5.93$ & 2.03 & $0.58,7.08$ & 3.21 & $1.20,8.56$ \\
\hline Poorer & $2.91^{* *}$ & $1.35,6.25$ & 2.46 & $0.71,8.51$ & 2.96 & $1.12,7.84$ \\
\hline Middle & 1.95 & $0.89,4.25$ & 3.04 & $0.88,10.54$ & 2.47 & $0.92,6.64$ \\
\hline Richer & $2.28^{*}$ & $1.09,4.77$ & 2.61 & $0.82,8.33$ & 2.30 & $0.90,5.88$ \\
\hline \multicolumn{7}{|l|}{ Mother education (higher education) } \\
\hline No education & 1.79 & $0.28,11.44$ & 0.26 & $0.03,2.10$ & 0.79 & $0.12,5.10$ \\
\hline Primary education & 2.02 & $0.32,12.74$ & 0.20 & $0.03,1.61$ & 0.87 & $0.14,5.55$ \\
\hline Secondary education & 2.68 & $0.42,17.05$ & 0.18 & $0.02,1.77$ & 0.54 & $0.07,3.94$ \\
\hline \multicolumn{7}{|l|}{ Child age (48-59 months) } \\
\hline $0-11$ months & 0.64 & $0.35,1.19$ & $3.11^{*}$ & $1.26,7.67$ & 0.79 & $0.40,1.56$ \\
\hline $12-23$ months & $1.67^{*}$ & $1.01,2.77$ & $2.53^{*}$ & $1.16,5.55$ & 0.99 & $0.55,1.76$ \\
\hline $24-35$ months & $2.00^{* *}$ & $1.29,3.10$ & 1.56 & $0.75,3.25$ & 1.56 & $0.95,2.54$ \\
\hline 36-47 months & 1.47 & $0.99,2.20$ & 0.74 & $0.34,1.61$ & 1.03 & $0.64,1.64$ \\
\hline \multicolumn{7}{|c|}{ Marital status (married/living together) } \\
\hline Never married/separated/widowed & 0.99 & $0.58,1.71$ & 1.42 & $0.58,3.51$ & 1.77 & $0.94,3.33$ \\
\hline Hosmer-Lemeshow test & 10.39 & & 7.71 & & 12.67 & \\
\hline$p$ values & 0.24 & & 0.46 & & 0.12 & \\
\hline
\end{tabular}

Reference categories are in parenthesis. ${ }^{*}$ Significant $p$ values $<0.05$; ${ }^{* *}$ significant $p$ values $<0.01$.

wasting, and underweight. This might be for the reason that low birth weight is in turn associated with a range of adverse outcomes of first childhood life.

Being born of a mother with a younger age at birth (less than 20 years) was associated with a lower risk of underweight compared to being born of mothers older than 20 years. This finding was in contradiction with the results of those children born of mothers at an earlier age having a higher chance of experiencing under-five underweight [38, 39].

Antenatal care visits during pregnancy were identified as a strong predictor of under-5 wasting in the multivariate analysis after controlling for the effect of other covariates. Results show that children born of mothers that do not attend any antenatal care service at the time of pregnancy have a significantly higher risk of wasting compared to those born of mothers that attended at least four antenatal visits. Previous research studies $[17,26,40]$ also revealed that antenatal follow-ups during pregnancy have been significantly associated with a reduced chance of wasting. The reason for this may be access to medical treatments for pregnancy which is helpful for the mother to protect her child from different infections. Another possible explanation for this result might be following antenatal care enables mothers to be aware of the advantages of breastfeeding and other feeding practices of their infants. Moreover, the World Health Organization also recommends that a woman should have at least four antenatal visits by health professionals during pregnancy.

Another significant risk factor attributed to stunting among under-five was wealth indices and source of improved drinking water. Children that were born in poor household were at the risk of stunting and underweight. The possible explanation for this might be mothers from households having the rich or middle wealth status were more likely to provide micronutrients in reached foods and seek medical treatment for their children. Previous literature also reported that the poor wealth index is strongly correlated with under-five stunting [15, 17, 23, 24, 26, 41, 42]. Furthermore, better of households has better access to food 
and higher cash incomes than poor households, allowing them a quality diet, better access to medical care, and more money to spend on essential nonfood items such as hygiene products. Similarly, unprotected sources of drinking water were strongly associated with a higher risk of stunting. This is consistent with available literature that states that improved sources of drinking water are a strong predictor of child stunting $[15,16,23]$.

Child diarrhea was found to be a significant association with wasting and underweight, such that children who had diarrhea in the last six months preceding the survey had an increased risk of wasting and underweight compared to those who did not have diarrhea. This finding is in agreement with studies $[17,24]$ which show a significant association with diarrhea recently and under-five wasting and underweight. This is due to the fact that diarrhea accelerates the onset of acute malnutrition by reducing food intake and increasing catabolic reactions in the organism.

On the other hand, the high number of under-five children in families was more likely to be associated with under-5 stunting and underweight. Various literature studies indicated that larger under-five children in households were significantly positively associated with stunting and wasting $[15,24]$. This may be because the large household size is widely regarded as a risk factor for stunting and underweight particularly for infants and young children due to food insecurity.

Age of a child was independently related to stunting and wasting. Similar previous research studies [23-25] reported that child age had a significant association with stunting and wasting of the children. Being a male child was highly positively associated with underweight. Studies have shown that boys had a significantly worse nutritional status than girls $[15,43,44]$. Mother's occupation, maternal or partner's education level, birth order, place of delivery, birth type, and mode of delivery were not significantly associated with experiencing stunting, wasting, and underweight.

\section{Conclusions}

Children from mothers who were not attending antenatal care during pregnancy were at higher risk of wasting. Thus, treatment of mothers during pregnancy should be given due attention. Children of age $0-11$ months and 12-23 months are more at risk of wasting. Thus, efforts should be made to communicate through health and nutrition education, the importance of feeding breast milk exclusively up to 6 months, and thereafter introducing other supplementary nutrient-rich foods.

Interventions that focus on children born with lower weight at birth $(<2.5 \mathrm{~kg})$ and children born in rural areas are required for improving the child stunting, wasting, and underweight though and improving healthcare services and food insecurity programs in rural areas. Children who use unprotected drinking water are at high risk of stunting. Thus, efforts should be made to improve access to safe drinking water. Children who have diarrhea two weeks before the date of the survey are significantly vulnerable to wasting and underweight than those who have not. Therefore, efforts should be made in improving environmental sanitation and personal hygiene to prevent exposure to diarrhea.

The authors also recommended further investigation based on trend analysis which had to be conducted to see the trend in under-five stunting, wasting, and underweight to achieve the sustainable development goal targets.

\section{Abbreviations \\ ANC: Antenatal care \\ CSA: Central Statistics Agency \\ EDHS: Ethiopian Demographic and Health Survey \\ HIV: Human immunodeficiency virus \\ MDG: Millennium Development Goal \\ NCHS: National Center for Health Statistics \\ SD: $\quad$ Standard deviation \\ WHO: World Health Organization \\ US: United States \\ USAID: United States Agency for International Development.}

\section{Data Availability}

The data used to support the findings of this study are available from the corresponding author upon request.

\section{Additional Points}

Since this study is based on secondary data onto EDHS 2016, some important variables may not be included in the study due to the incompleteness of data (high missing values). Moreover, this study uses mothers' recalls of babies, so there may be recalled bias.

\section{Conflicts of Interest}

The authors declare that they have no conflicts of interest.

\section{Authors' Contributions}

TT was involved from the inception to design and in acquisition of data, analysis and interpretation, and drafting the manuscript. BT was involved from the inception to design and in analysis and interpretation, revising critically the manuscript, and editing the manuscript for the final submission. Both authors read and approved the final manuscript.

\section{Acknowledgments}

The authors are grateful to ICF Macro (Calverton, USA) for providing the 2016 DHS data of Ethiopia.

\section{References}

[1] UNICEF/WHO/World Bank Group, Joint Child Malnutrition Estimates 2017 Edition, UNICEF/WHO/World Bank Group, Geneva, Switzerland, 2017.

[2] UNICEF/WHO/World Bank Group, Joint Child Malnutrition Estimates 2018 Edition, UNICEF/WHO/World Bank Group, Geneva, Switzerland, 2017. 
[3] Global Humanitarian Assistance Programme, Development Initiatives) Country, North Quay house Quay side Temple Back, Bristol, UK, 2018.

[4] UNICEF, Malnutrition Rates Remain Alarming: Stunting is Declining Too Slowly while Wasting Still Impacts the Lives of Far Too Many Young Children, UNICEF, New York, NY, USA, 2018.

[5] B. J. Akombi, K. E. Agho, D. Merom, A. M. Renzaho, and J. J. Hall, "Child malnutrition in sub- Saharan Africa: a metaanalysis of demographic and health surveys (2006-2016)," PLoS One, vol. 12, no. 5, Article ID e0177338, 2017.

[6] WHO, World Health Statistics Report, World Health Organization, Geneva, Switzerland, 2010.

[7] United Nations, The Millennium Development Goals Report, United Nations, Geneva, Switzerland, 2015.

[8] Ethiopia Central Statistical Agency (CSA), Ethiopia Demographic and Health Survey 2016, Central Statistical Agency, Addis Ababa \& ICF International, Calverton, MD, USA, 2016.

[9] A. Abdulahi, S. Shab-Bidar, S. Rezaei, and K. Djafarian, "Nutritional status of under five children in Ethiopia: a systematic review and meta-analysis," Ethiopian Journal of Health Sciences, vol. 27, no. 2, pp. 175-188, 2017.

[10] A. mulugeta, F. hagos, G. Kruseman et al., "Child malnutrition in Tigray, Northern Ethiopia," East African Medical Journal, vol. 87, no. 6, 2010.

[11] H. Gerensea, T. Berhe, and H. Siyum, "Trend of malnutrition in Tigray region from 2011/12-2014/15," Journal of Anesthesia \& Clinical Research, vol. 8, no. 5, pp. 1-4, 2017.

[12] H. Brhane, B. Mohammed, H. Y. Yeshita, and K. A. Gonete, "Prevalence and associated factors of acute malnutrition among 6-59 month children in adi-harush and Hitsats refugee camps in Tigray region Northern Ethiopia, 2017," American Journal of Life Sciences, vol. 6, no. 5, pp. 57-64, 2018.

[13] Z. Y. Kassa, T. Behailu, A. Mekonnen, M. Teshome, and S. Yeshitila, "Malnutrition and associated factors among under five children (6-59 months) at shashemene referral hospital, West Arsi zone, Oromia, Ethiopia," Current Pediatric Research, vol. 21, no. 1, pp. 172-180, 2017.

[14] A. Zeray, G. D. Kibret, and C. T. Leshargi, "Prevalence and associated factors of undernutrition among under-five children from model and non-model households in east Gojjam zone, Northwest Ethiopia: a comparative cross-sectional study," BMC Nutrition, vol. 5, no. 27, 2019.

[15] G. G. Poda, C.-Y. Hsu, and J. C.-J. Chao, "Factors associated with malnutrition among children," International Journal for Quality in Health Care, vol. 29, no. 7, pp. 901-908, 2017.

[16] T. Wolde, E. Adeba, and A. Sufa, "Prevalence of chronic malnutrition (stunting) and determinant factors among children aged 0-23 months in Western Ethiopia: a crosssectional study," International Journal of Nutritional Disorders \& Therapy, vol. 4, no. 4, pp. 1-7, 2014.

[17] D. Amare, A. Negesse, B. Tsegaye, B. Assefa, and B. Ayenie, "Prevalence of undernutrition and its associated factors among children below five years of age in Bure Town, West Gojjam zone, Amhara National regional state, Northwest Ethiopia," Advances in Public Health, vol. 2016, Article ID 7145708, 8 pages, 2016.

[18] A. E. Yawson, E. O. Amoaful, L. K. Senaya et al., "The lancet series nutritional interventions in Ghana: a determinants analysis approach to inform nutrition strategic planning," BMC Nutrition, vol. 3, no. 27, pp. 1-8, 2017.

[19] Z. Ali, M. Saaka, A. G. Adams, S. K. Kamwininaang, and A. R. Abizari, "The effect of maternal and child factors on stunting, wasting and underweight among preschool children in Northern Ghana," BMC Nutrition, vol. 3, no. 31, pp. 1-13, 2017.

[20] C. M. Sobgui, L. K. Fezeu, F. Diawara, H. Diarra, V. Afari-Sefa, and A. Tenkouano, "Predictors of poor nutritional status among children aged 6-24 months in agricultural regions of Mali: a cross-sectional study," BMC Nutrition, vol. 4, no. 1, pp. 1-13, 2018.

[21] G. Berhanu, S. Mekonnen, and M. Sisay, "Prevalence of stunting and associated factors among preschool children: a community based comparative cross sectional study in Ethiopia," BMC Nutrition, vol. 4, no. 28, pp. 1-15, 2018.

[22] A. Ma'alin, D. Birhanu, S. Melaku, D. Tolossa, Y. Mohammed, and K. Gebremicheal, "Magnitude and factors associated with malnutrition in children 6-59 months of age in Shinille Woreda, Ethiopian Somali regional state: a cross-sectional study," BMC Nutrition, vol. 2, no. 1, pp. 1-12, 2016.

[23] M. Amare, T. Benson, O. Fadare, and M. Oyeyemi, "Study of the determinants of chronic malnutrition in Northern Nigeria: quantitative evidence from the Nigeria demographic and health surveys international food policy research institute (IFPRI) working paper 45 (September 2017)," Food and Nutrition Bulletin, vol. 39, no. 2, pp. 296-314, 2018.

[24] A. Awoke, M. Ayana, and T. Gualu, "Determinants of severe acute malnutrition among under five children in rural Enebsie Sarmidr District, East Gojjam zone, NorthWest Ethiopia," BMC Nutrition, vol. 4, no. 1, pp. 1-8, 2016.

[25] L. D. Nzefa, F. Monebenimp, and C. Äng, "Undernutrition among children under five in the Bandja village of Cameroon, Africa," South African Journal of Clinical Nutrition, vol. 32, no. 2, pp. 46-50, 2019.

[26] A. Talukder, "Factors associated with malnutrition among under-five children: illustration using Bangladesh Demographic and Health Survey, 2014 Data," Journal of Children, vol. 4, no. 10, pp. 1-8, 2017.

[27] M. M. Ahmed, A. Hokororo, B. R. Kidenya, R. Kabyemera, and E. Kamugisha, "Prevalence of undernutrition and risk factors of severe undernutrition among children admitted to Bugando Medical Centre in Mwanza, Tanzania," BMC Nutrition, vol. 2, no. 1, pp. 1-6, 2016.

[28] E. S. Rose, M. Blevins, L. González-Calvo, E. Ndatimana, A. F. Green, and M. Lopez, "Determinants of undernutrition among children aged 6 to 59 months in rural Zambézia Province, Mozambique: results of two population-based serial cross-sectional surveys," BMC Nutrition, vol. 1, no. 1, pp. 1-11, 2015.

[29] A. Mukabutera, D. R. Thomson, B. L. Hedt-Gauthier, P. Basinga, L. Nyirazinyoye, and M. Murray, "Risk factors associated with underweight status in children under five: an analysis of the 2010 Rwanda Demographic Health Survey (RDHS)," BMC Nutrition, vol. 2, pp. 1-12, 2016.

[30] M. Saaka, A. Larbi, S. Mutaru, and I. Hoeschle-Zeledon, "Magnitude and factors associated with appropriate complementary feeding among children 6-23 months in Northern Ghana," BMC Nutrition, vol. 2, no. 1, pp. 1-8, 2016.

[31] A. E. Yawson, E. O. Amoaful, L. K. Senaya, A. O. Yawson, P. K. Aboagye, and A. B. Mahama, "The lancet series nutritional interventions in Ghana: a determinants analysis

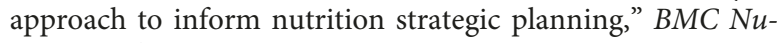
trition, vol. 3, no. 1, pp. 1-8, 2017.

[32] Ethiopia Central Statistical Agency (CSA), Population and Housing Census, CSA, Addis Ababa, Ethiopia, 2007.

[33] K. Mengistu, K. Alemu, and B. Destaw, "Prevalence of malnutrition and associated factors among children aged 6-59 months at Hidabu Abote District, North shewa, Oromia 
regional state," Journal of Nutrition Disorders \& Therapy, vol. 1, no. 1, pp. 1-15, 2013.

[34] N. Endris, H. Asefa, and L. Dube, "Prevalence of malnutrition and associated factors among children in rural Ethiopia," BioMed Research International, vol. 2017, Article ID 6587853, 6 pages, 2017.

[35] A. Emmanuel, N. O. Juliet, O. E. Adetunji, G. K. Hosea, and K. R. Partience, "Malnutrition and associated factors among underfive in a Nigeria local government area," International Journal of Contemporary Medical Research, vol. 3, no. 6, pp. 1766-1768, 2016.

[36] T. G. Okari, A. R. Nte, and A. I. Frank-Briggs, "Prevalence of malnutrition among under-fives in Okrika Town, Nigeria," IOSR Journal of Dental and Medical Sciences (IOSR-JDMS), vol. 18, no. 1, pp. 40-45, 2019.

[37] M. I. Rayhan and M. S. Khan, "Factors causing malnutrition among under-five children in Bangladesh," Pakistan Journal of Nutrition, vol. 5, no. 6, pp. 1-5, 2006.

[38] A. S. Nure, H. Nuruzzaman, and G. Abdul, "Mulnutrition of underfive children: evidence from Bangladesh," Asian Journal of Medical Sciences, vol. 2, pp. 113-119, 2011.

[39] R. O. Babatunde, F. I. Olagunju, S. B. Fakayode, and F. E. SolaOjo, "Prevalence and determinants of malnutrition among under-five children of farming households in Kwara State," Journal of Agricultural Science, Nigeria, vol. 3, no. 3, pp. 1-9, 2011.

[40] S. Das and R. M Rahman, "Application of ordinal logistic regression analysis in determining risk factors of child malnutrition in Bangladesh," Nutrition Journal, vol. 10, no. 1, 2011.

[41] B. Gezae and R. Nigatu, "Nutritional status of children under five years of age in Shire Indaselassie, North Ethiopia: Examining the prevalence and risk factors," Kontakt, vol. 16, no. 3, pp. e161-e170, 2014.

[42] D. Dereje and T. Ayele, "Nutritional status of under- five children in Hawassa Zuria District, Southern Ethiopia," American Journal of Health Research, vol. 3, no. 5, pp. 286292, 2015.

[43] M. Alemu, J. Nicola, and T. Bekele, "Tackling child malnutrition in Ethiopia: do the sustainable development poverty reduction program's underlying policy assumptions reflect local realities? Young lives, an international study of childhood poverty," Working paper No. 19, 2005.

[44] H. Wamani, A. N. Astrom, S. Peterson, J. K. Tumwine, and T. Tylleskar, "Boys are more stunted than girls in Sub-Saharan Africa: a meta analysis of 16 demographic and health surveys," BMC Pediatrics, vol. 7, no. 1, pp. 1-10, 2007. 


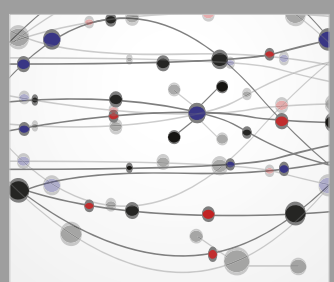

The Scientific World Journal
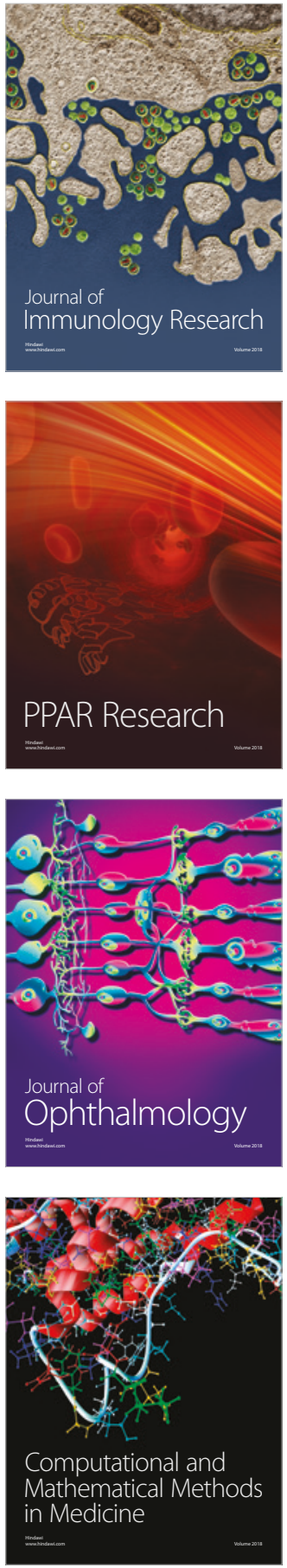

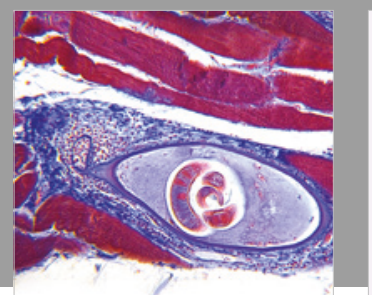

Gastroenterology Research and Practice

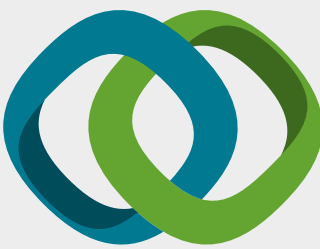

\section{Hindawi}

Submit your manuscripts at

www.hindawi.com
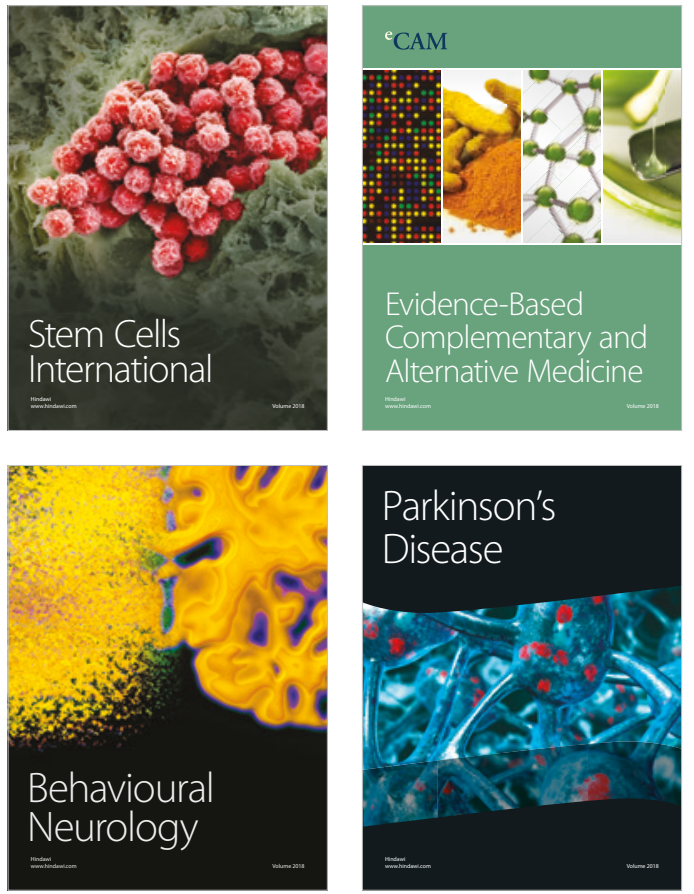

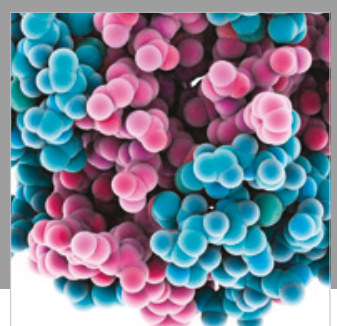

ournal of

Diabetes Research

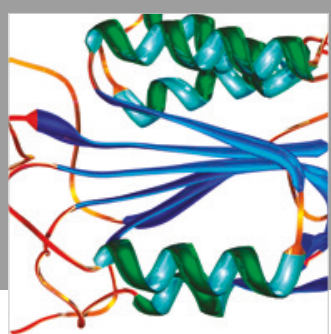

Disease Markers
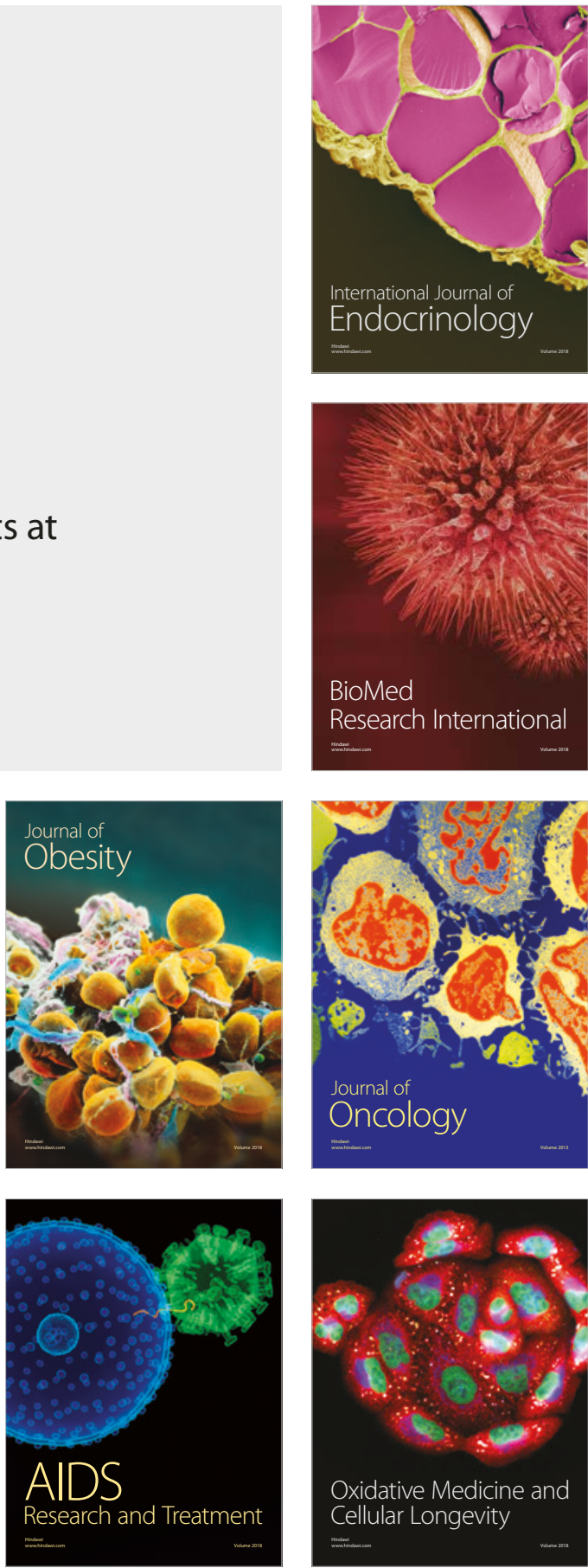